
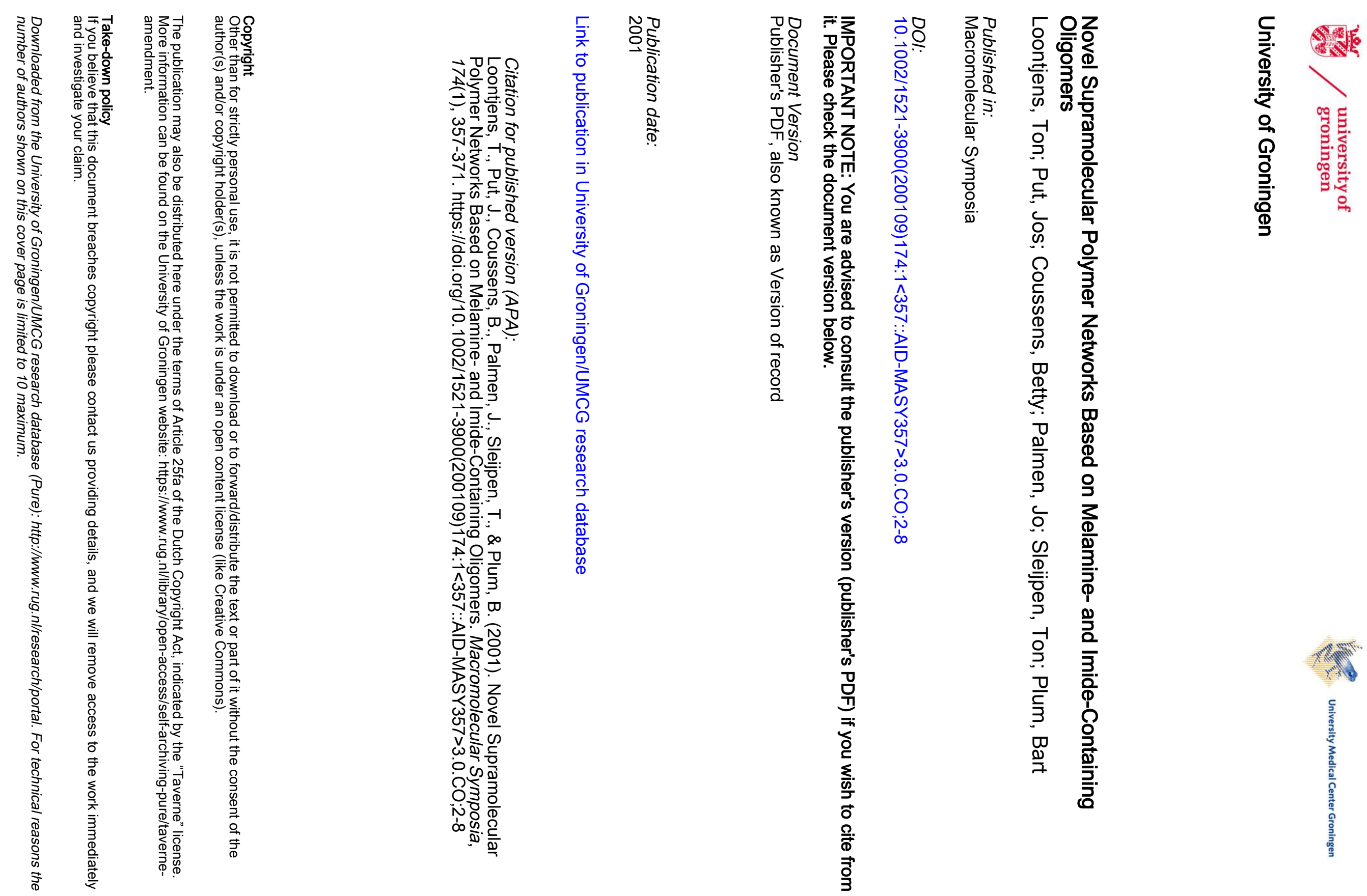


\title{
Novel Supramolecular Polymer Networks Based on Melamine- and Imide-Containing Oligomers
}

\author{
Ton Loontjens*, Jos Put, Betty Coussens, Ronald Lange, Jo Palmen, Ton Sleijpen \\ and Bart Plum
}

DSM Research, P.O. Box 18, 6160 MD Geleen, Netherlands

Ton.Loontjens@DSM-group.com

\begin{abstract}
SUMMARY: Reversible, supramolecular polymer networks based on commercially available bulk chemicals, and prepared using an industrially attractive route are described. The difunctional, low molecular weight polytetramethyleneoxide is functionalized with trimellitic imide, and reversibly crosslinked with the trifunctional melamine using the well known imide-diaminopyridine triple hydrogen bonding pattern. Molecular modelling calculations as well as experimental studies on model compounds indicate that the aimed 1:3 melamine - imide stoichiometry is obtained. The resulting reversible, supramolecular polymer structures show a rheological behaviour, that is typical for polymer networks. The results presented here describe an industrially accessible route to use supramolecular interactions in order to obtain materials with novel properties.
\end{abstract}

\section{Introduction}

Within the field of supramolecular chemistry, hydrogen bonding is often used to obtain greater control over the self-assembly process of different molecules like in e.g. well-defined (cyclic) arrays or container molecules. ${ }^{1,2)}$ Different hydrogen bonding arrays possessing various interaction strengths are used, and despite the relative weak interaction of the DAD-ADA triple hydrogen bond array, where $\mathrm{A}$ stands for hydrogen acceptor and $\mathrm{D}$ for hydrogen donor, this motif is frequently used due to it's synthetic availability. ${ }^{3)}$ The DAD-ADA array can be obtained using the complexation of imides with 2,6-diaminopyridine- or melamine derivatives, and is well described. $^{2,4)}$ Due to the very stable, hydrogen bonded, crystal structure of melamine, results dealing with the supramolecular complexation of pure melamine are scarce. ${ }^{5,6}$ However, melamine based polymer networks are obtained using styrene-maleimide copolymers, and the 3:1 imide-melamine stoichiometry was supported by model studies. ${ }^{6 b}$

While in the field of organic chemistry supramolecular chemistry is used aiming at a more detailed knowledge of molecular processes like e.g. self-replicating systems, ${ }^{7)}$ and provides insight into natural self-assembly, supramolecular chemistry used in the field of polymer 
chemistry is aiming to obtain materials with novel and exciting properties. Main- and side-chain supramolecular polymers, and reversible, hydrogen bonded polymer networks are prepared. The hydrogen bonding arrays used in these supramolecular polymers are often based on relative weak interactions like the DAD-ADA array, acid-acid, and acid-pyridine interactions. ${ }^{6,8-13)}$ Due to these relative weak interactions, an additional phase separation like a liquid crystalline phase, crystallisation or the use of polymers possessing a $T_{g}$ above room temperature have to be used to stabilise the polymer network. Using a stronger hydrogen bonding interaction like the selfcomplementary ureido-pyrimidone unit, polymeric properties are obtained without the support of additional phenomena such as e.g. phase separation. ${ }^{14)}$

Here we present a supramolecular polymer network based on polymers possessing a low glass transition temperature $\left(\mathrm{T}_{\mathrm{g}}\right)$, which are connected via melamine using the relatively weak imide melamine DAD-ADA triple hydrogen bond. The main advantage of this approach compared to already known examples is that all building blocks are commercially available bulk chemicals, in combination with an industrially attractive synthetic route, as is depicted in Scheme 1.
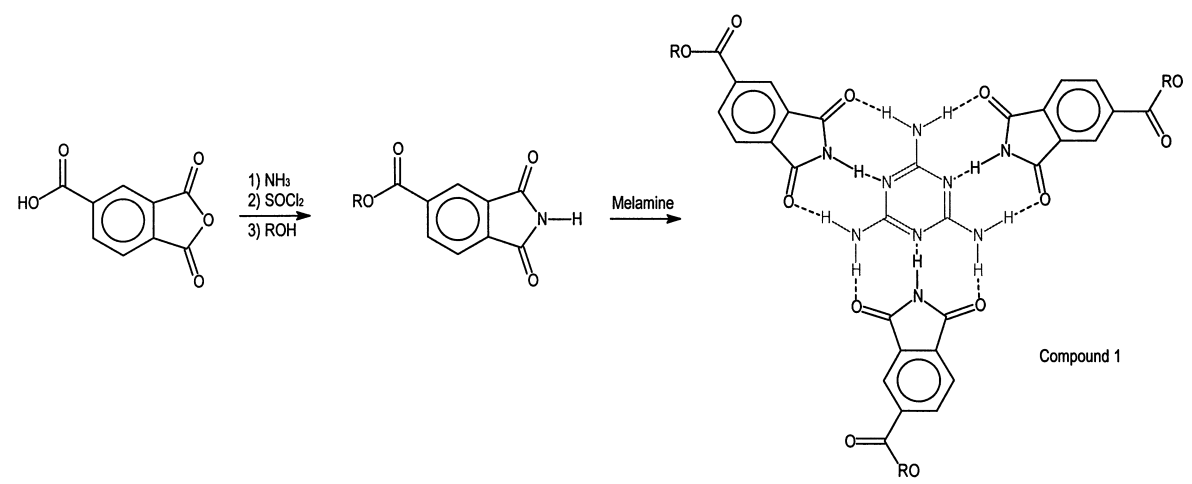

Scheme 1. Supramolecular polymer network based on the imide - melamine DAD-ADA triple hydrogen bond.

\section{Results and discussion}

\section{Modelling}

The supramolecular network depicted in Scheme 1 is based on the imide of trimellitic anhydride (TMI) and melamine. One may wonder whether this imide is the most suitable for our purpose, i.e. maybe much stronger hydrogen bonds are formed with melamine when other imides are used. Two modifications of TMI can easily be envisaged: (1) a sixmembered imide instead of a fivemembered one and (2) the addition of electron-withdrawing or electron-donating substituents on 
TMI. The importance of such modifications have been investigated by performing Hartree-Fock calculations on the 1:1 complexes of melamine with TMI, 5-nitro-TMI, 5-methoxy-TMI and 3,4benzoglutaric imide. The calculated binding energies for these systems are listed in Table 1.

Table 1. Binding energies $(\mathrm{kJ} / \mathrm{mol})$ for the 1:1 complexes of melamine with TMI, 5-nitro-TMI, 5-methoxy-TMI and 3,4-benzoglutaric imide.

\begin{tabular}{|l|c|}
\hline Imide & Binding energy \\
\hline TMI & -56.78 \\
5-nitro-TMI & -57.57 \\
5-methoxy-TMI & -55.90 \\
3,4-benzoglutaric imide & -60.50 \\
\hline
\end{tabular}

From a quantitative point of view, the numbers of Table 1 are certainly prone to quite large errors as they are based on simple Hartree-Fock calculations. However, it is perfectly valid to use them in a qualitative sense, i.e. for making predictions regarding the relative effect of the TMI modifications on the strength of the 1:1 complex. As can be seen, the electron withdrawing nitro group results in a somewhat stronger complex whereas the electron donating methoxy group results in a slight weakening of the complex. In both cases, however, the maximum change in binding energy is negligible. It amounts to only ca. $0.9 \mathrm{~kJ} / \mathrm{mol}$. A larger effect is seen when the imide ring is changed from a five-membered to a six-membered ring. The binding energy now increases by ca. $3.7 \mathrm{~kJ} / \mathrm{mol}$. This is a direct consequence of a better structural fit of the sixmembered ring. Indeed, for the $\mathrm{C}=\mathrm{O}---\mathrm{HN}$ hydrogen bonds to be optimal the $\mathrm{NH}$ hydrogens should point toward the oxygen lone pairs of the $\mathrm{C}=\mathrm{O}$ groups making an angle of $120^{\circ}$ with respect to the $\mathrm{C}=\mathrm{O}$ bond. Such an optimal arrangement is possible when the imide group is part of the six membered glutaric imide but it is not for TMI. Still, we decided that an increase in binding energy of only $3.7 \mathrm{~kJ} / \mathrm{mol}$ does not count heavily enough to give up the big advantage of the commercial availability of TMI.

Quantumchemical calculations have also been performed in order to find out whether the binding of a second and third TMI molecule with melamine is influenced by the TMI molecule(s) already present in the complex. Thus, also the 1:2 and 1:3 complexes of melamine with TMI were investigated. The possible mutual effect of the TMI molecules was studied by : (1) calculating the binding energy for each additional TMI molecule, (2) looking in detail at possible changes of the relevant geometrical parameters in the hydrogen bonding units as a function of the number of TMI molecules and (3) investigating possible changes of the electron distribution in the hydrogen bonding units as the number of TMI molecules increases. 
Table 2 shows the results of the binding energy calculations. As can be seen, the binding energy of the second TMI molecule is somewhat smaller than that of the first one and somewhat larger than that of the third one. However, the maximum change is calculated to be only ca. $6.4 \mathrm{~kJ} / \mathrm{mol}$. An inspection of the geometrical parameters did not reveal any significant change on going from the $1: 1$ to the $1: 2$ and 1:3 complex. The potential energy surface turns out to be very flat and therefore these parameters are not sufficiently accurate to allow conclusions regarding the mutual influence of the TMI molecules on their binding properties with melamine.

Table 2. Binding energies $(\mathrm{kJ} / \mathrm{mol})$ for TMI molecules in the various complexes of TMI with melamine (M).

\begin{tabular}{|l|c|}
\hline Reaction & Reaction (binding) energy \\
\hline $\mathrm{M}+\mathrm{TMI} \rightarrow \mathrm{M}: \mathrm{TMI}$ & -56.78 \\
$\mathrm{M}: \mathrm{TMI}+\mathrm{TMI} \rightarrow \mathrm{M}: \mathrm{TMI}_{2}$ & -53.30 \\
$\mathrm{M}: \mathrm{TMI}_{2}+\mathrm{TMI} \rightarrow \mathrm{M}: \mathrm{TMI}_{3}$ & -50.42 \\
\hline
\end{tabular}

Table 3 shows the results of a Mulliken population analysis. The notation of the atoms in Table 3 is depicted in Scheme 2. The numbers listed are the changes in the partial charges on the different atoms as a consequence of the binding process. Schematically this redistribution of charge as a result of hydrogen bonding can be represented as :

$$
\begin{array}{lrrr}
\delta+\delta- & \delta+\delta- & \delta- & \delta+\delta- \\
\mathrm{C}=\mathrm{O}-----\mathrm{H}-\mathrm{N} & \mathrm{N}---\mathrm{H}-\mathrm{N}
\end{array}
$$

with $\delta+$ denoting an increase of the atomic partial charge (and thus a decrease of the electron density) and $\delta$ - denoting a decrease of the partial charge (and thus an increase of the electron density). These changes result on the one hand from a redistribution of charge within the molecules themselves (polarisation effect) and on the other hand from a transfer of electrons from one molecule to another, the first effect being significantly larger than the second one. In the TMI-melamine complexes electrons are transferred from melamine to TMI. As can be seen in Table 3, this total number of electrons is found to be $0.017,0.028$ and 0.033 for the $1: 1,1: 2$ and 1:3 complexes, respectively. The fact that it is not twice, respectively three time as large in the 1:2 and 1:3 complex than in the 1:1 complex illustrates that the TMI molecules indeed influence each other. This mutual influence is also observed when looking at the data for the TMI unit (not included in Table 3). 
<smiles>CNc1nc(N(C)C)nc(N(C)C)n1</smiles>

Sheme 2. Notation of melamine atoms

Table 3. Changes in the atomic partial charges as a consequence of hydrogen bonding of the melamine (M) atoms. Numbers indicated in bold + italics indicate 1 hydrogen bond for the $\mathrm{CNH}_{2}$ group, bold indicates two hydrogen bonds.

\begin{tabular}{|l|l|l|l|}
\hline Atom & M + TMI & M + 2 TMI & M + 3 TMI \\
\hline N1 & $\mathbf{- 0 . 1 1 6}$ & $\mathbf{- 0 . 1 1 1}$ & $\mathbf{- 0 . 1 1 2}$ \\
\hline C1 & $\mathbf{0 . 0 5 5}$ & $\mathbf{0 . 1 0 4}$ & $\mathbf{0 . 1 0 1}$ \\
N12 & $\mathbf{- 0 . 0 1 2}$ & $\mathbf{- 0 . 0 2 4}$ & $\mathbf{- 0 . 0 2 3}$ \\
H1 & $\mathbf{0 . 0 1 8}$ & $\mathbf{0 . 0 2 0}$ & $\mathbf{0 . 0 2 3}$ \\
H12 & 0.003 & $\mathbf{0 . 0 2 4}$ & $\mathbf{0 . 0 2 4}$ \\
\hline N2 & 0.000 & -0.112 & -0.112 \\
\hline C2 & -0.002 & $\mathbf{0 . 0 4 9}$ & $\mathbf{0 . 1 0 0}$ \\
N22 & 0.002 & $\mathbf{- 0 . 0 0 9}$ & $\mathbf{- 0 . 0 2 2}$ \\
H2 & 0.002 & $\mathbf{0 . 0 1 7}$ & $\mathbf{0 . 0 2 0}$ \\
H22 & 0.002 & 0.005 & $\mathbf{0 . 0 2 5}$ \\
\hline N3 & 0.000 & 0.002 & $\mathbf{- 0 . 1 1 0}$ \\
\hline C3 & $\mathbf{0 . 0 5 5}$ & $\mathbf{0 . 0 4 8}$ & $\mathbf{0 . 0 9 9}$ \\
N32 & $\mathbf{- 0 . 0 1 2}$ & $\mathbf{- 0 . 0 0 9}$ & $\mathbf{- 0 . 0 1 9}$ \\
H3 & 0.003 & 0.004 & $\mathbf{0 . 0 1 8}$ \\
H32 & $\mathbf{0 . 0 1 9}$ & $\mathbf{0 . 0 2 0}$ & $\mathbf{0 . 0 2 1}$ \\
\hline Melamine & 0.017 & 0.028 & 0.033 \\
\hline
\end{tabular}

E.g. the partial charge on C1T (carbonyl carbon) is found to increase by $0.012,0.010$ and 0.007 in the 1:1, 1:2 and 1:3 complex, respectively. The corresponding decrease for O1T (carbonyl oxygen) is $-0.049,-0.047$ and -0.040 . In general the small changes in the atomic partial charges clearly reveal a slight weakening of the melamine-TMI hydrogen bonds when more TMI molecules are added. The fact that the changes are small is in agreement with the observation that the redistribution of electron density upon binding is almost entirely local, i.e. for the atoms which are not involved in the binding process the redistribution of the electron density is negligible. It is also in agreement with the rather small change in binding energy as the number of TMI molecules increases (see Table 2).

It can thus be concluded that the TMI molecules do influence each other and that the binding of TMI with melamine becomes weaker as the number of TMI molecules increases, but this weakening is small. 
Unfortunately, our theoretical calculations do not allow for a definite answer on the question whether the 1:3 complex of melamine with TMI will really exist. Indeed, the calculations only provide qualitative information on the reaction enthalpies at $0 \mathrm{~K}$ in the gas phase. For answering the above question, entropic effects should be taken into account as well. Obviously, as the 1:3 complex is formed, the entropy will significantly drop and therefore the free energy of reaction at a given temperature will be considerably smaller than the enthalpy of reaction. In principle, the entropy change can be calculated by using formulae from statistical mechanics when the vibrational frequencies of the systems are known. ${ }^{11)}$ However, frequency analyses for the huge complexes considered here are not realistic; they are extremely time-consuming and need lots of diskspace. Furthermore, even if such analyses could be performed, other factors which also play an important role would still have to be neglected such as the binding energy of melamine in the crystal lattice.

\section{Synthesis}

Due to the difficult analysis of high molecular weight compounds, model compounds were used to optimise and control the preparation methods. Furthermore, using these model compounds the complex stoichiometry between melamine and the imide functionalized low $\mathrm{T}_{\mathrm{g}}$ polymers can be determined more accurately.

In order to obtain a versatile system to prepare reversible supramolecular networks from commercial available bulk chemicals, the well-known DAD-ADA hydrogen bonding motif is used to complex the industrial available melamine with the imide of trimellitic anhydride, where the free carboxilic acid group gives the freedom of designing the properties of the aimed supramolecular polymer network. Estrification of the free carboxilic acid group with diols or tiols leads to a whole family of compounds

The synthesis of the imide of trimellitic anhydride is rather simple starting from trimellitic anhydride and ammonium carbonate. Ammonium carbonate decomposes at $280^{\circ} \mathrm{C}$ into carbon dioxide, water and ammonia. The ammonia reacts fast with the anhydride to the amide-acid and, under the conditions applied, the ring closing reaction takes place immediately. All the gaseous compounds such as water, carbon dioxide and the excess of ammonia, as well as the excess of the ammonium carbonate, that is completely decomposed, are removed by a nitrogen stream. Since the reactions go to completion and all the side products are gaseous, no purification step is needed and the product can be used as obtained. In a consecutive step the acid group of TMI is converted into the acid chloride with thionyl chloride. Again, this 
reaction proceeds smoothly and goes to completion. The excess of thionyl chloride is removed by destillation. All the imide functional esters that are used in this work were prepared by heating the acid chloride and the alcohols in toluene as solvent. Since the reactants and the products are not basic and don't react with the formed hydrochloric acid, it was possible to remove this gaseous reactant by a nitrogen stream. This is a very convenient way to remove the hydrogen chloride from the reaction mixture. No further purification steps are needed because these reactions are quantitatively. The ester oligomers are isolated by removing the solvent by destillation.

Finally, the supramolecular complexes are made by either melt blending or in solution. Melt blending is of course the most advantageous way to prepare the complexes in an industrial way. However, at the start of this study it was thought, that the solvent based route might lead to more homogeneous products. But, within the limits of our experiments, no clear differences were found and therefore most of the results reported here were obtained by the melt blend method.

As an example for the nomenclature, the ester of hexanol and TMI is named hexanol-TMI and the complex of melamine and hexanol-TMI is presented as hexanol-TMI-melamine.

\section{Analysis}

The most reliable method to prove the existence of supramolecular complexes is to determine the crystal structure of single crystals by X-ray diffraction. However, all attempts to obtain suitable single crystals failed. In order to gather evidence to prove the existence of the supramolecular structures, we therefore studied our complexes with a variety of analytical techniques, such as IR, NMR, X-ray diffraction, DSC and DMS.

IR spectra were recorded of melamine and the hexanol-TMI-melamine complex. The NH stretch of melamine gives rise to two very sharp signals at 3420 and $3475 \mathrm{~cm}^{-1}$. After melt blending this product with melamine the sharp absorption peaks become one broad peak, although hexanol-TMI has no absorption in this region. This indicates the involvement of the melamine- $\mathrm{NH}_{2}$ group in the hydrogen bond with the imide. Unfortunately, it was not possible to observe shifts in the carbonyl region, because the absorption of the carbonyl group of the imides and those of the esters show some overlap.

The ${ }^{1} \mathrm{H}-\mathrm{NMR}$ spectra of hexanol-TMI, melamine and the complex were recorded in DMSO (dimethylsulfoxide). DMSO is one of the few solvents in which melamine dissolves to a substantial extent. It is interesting to see (Fig. 1) that, although DMSO breaks hydrogen 
bonds, the sharp singlet at $11.65 \mathrm{ppm}$ of the $\mathrm{NH}$ of the imide becomes quite broad on the addition of melamine. This is a strong indication that the $\mathrm{NH}$ of the imide is involved in the complexation reaction with melamine. These results suggest again, that interactions are taken place between these two molecules by hydrogen bonding, even in such a strong polar solvent as DMSO.
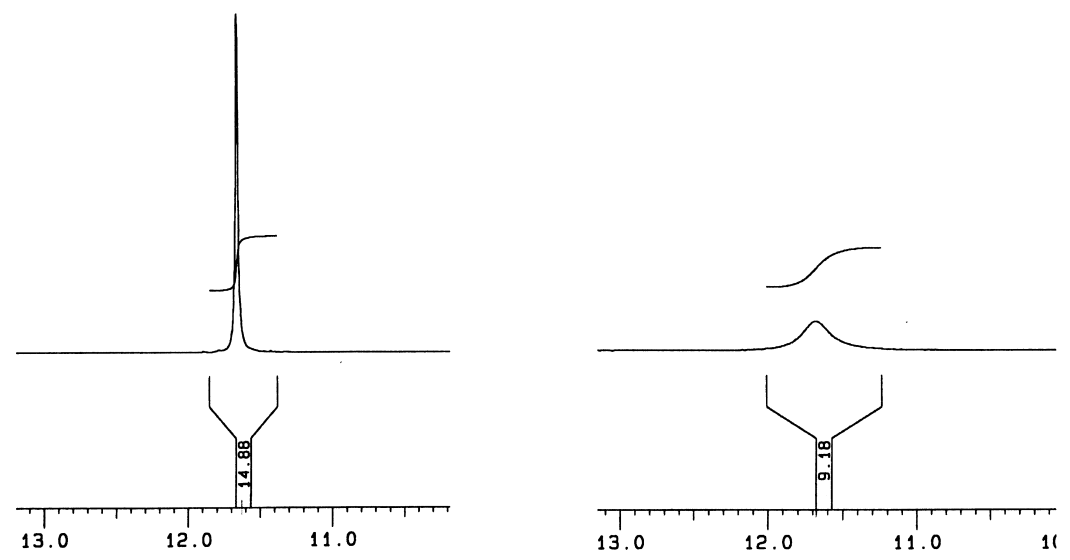

Figure 1. Low field part of the ${ }^{1}$ H-NMR spectrum of hexanol-TMI (a) and the mixture of hexanol-TMI and melamine (b) in d6-DMSO.

For the thermal investigations we prepared a series of products in which $\mathrm{C}_{6}, \mathrm{C}_{8}, \mathrm{C}_{12}$ and $\mathrm{C}_{16}$ mono functional alcohols were esterified with the acid chloride of TMI. The DSC results shown in Table 4 are obtained with a scanning rate of $10^{\circ} \mathrm{C} / \mathrm{min}$. Only the second melting temperature is given to exclude the history of the sample. The melting behaviour in the second and all the next scans were the same. The melting points of the imide and the complexes are quite similar. This suggests that the melting behaviour is determined by the TMI unit. The increase of the melting enthalpy with the length of the alkyl chain suggests that the melting enthalpy is determined by the paraffinic part of the complex. Large differences can be seen in the crystallisation temperature. The crystallisation temperature of the complexes are much lower than those of the corresponding TMI esters. This could be rationalised by the fact that during the cooling step the formation of the complex has to take place. That delays the crystallisation and hence decreases the crystallisation temperature. DSC scans with a slower cooling rates, that might lead to higher crystallization temperatures of the complexes, have to be done to prove this hypothesis. 
Table 4. The thermal (DSC) data of a series of TMI-melamine complexes.

\begin{tabular}{|l|l|l|l|l|l|}
\hline \multicolumn{3}{|c|}{ Pure $\mathrm{C}_{\mathrm{x}}-\mathrm{TMI}$} & $3: 1$ complex (TMI:Melamine) \\
\hline Sample & $\begin{array}{l}\mathrm{T}_{\mathrm{m} 2} \\
\left({ }^{\circ} \mathrm{C}\right)\end{array}$ & $\begin{array}{l}\Delta \mathrm{H} \\
(\mathrm{J} / \mathrm{g})\end{array}$ & $\begin{array}{l}\mathrm{T}_{\mathrm{c}} \\
\left({ }^{\circ} \mathrm{C}\right)\end{array}$ & $\begin{array}{l}\mathrm{T}_{\mathrm{m} 2} \\
\left({ }^{\circ} \mathrm{C}\right)\end{array}$ & $\begin{array}{l}\mathrm{T}_{\mathrm{c}} \\
\left({ }^{\circ} \mathrm{C}\right)\end{array}$ \\
\hline C6 (2) & 131 & 100 & 77 & $124 / 143$ & 56 \\
$\mathrm{C} 8(\mathbf{3 )}$ & 131 & 129 & 90 & 128 & 72 \\
$\mathrm{C} 12 \mathbf{( 4 )}$ & 135 & 134 & 102 & 132 & 93 \\
$\mathrm{C} 16(\mathbf{5})$ & 135 & 163 & 105 & 133 & 83 \\
\hline
\end{tabular}

In the complex with hexanol-TMI (2) two melting peaks are observed. For the moment we don't have a good explanation for this phenomenon. A liquid crystalline behaviour can be excluded, since no birefringment can be seen in a hot stage optical microscope. Thus, also the thermal studies indicate that physical interactions between TMI and melamine exist.

More convincing evidence came from X-ray data. Melamine is hardly soluble in any solvent and is a highly crystalline substance with a characteristic X-ray spectrum. Lange et al. ${ }^{6}$ have shown that the part of the melamine that doesn't dissolve in a polymer can easily be detected by X-ray diffraction measurements. In Fig. 2 the amount of melamine detected by X-ray diffraction is plotted against the total amount of melamine that is added to hexanol-TMI.

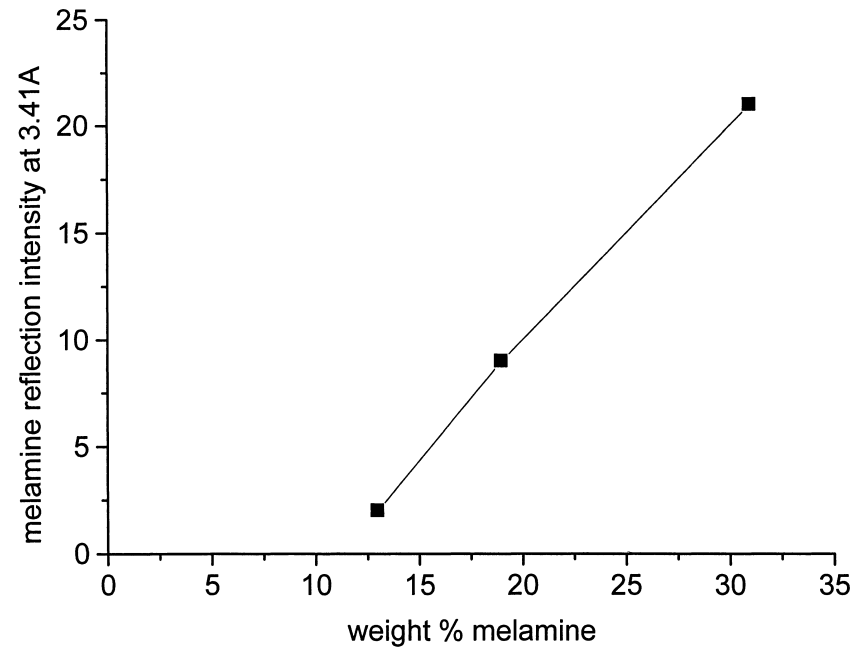

Figure 2. Graph of the total amount of melamine added to hexanol-TMI versus the amount of crystalline melamine measured by X-ray diffraction. 
The X-ray diffraction measurements show only the crystalline part of melamine. Extrapolation of the line to zero, for the amount of melamine determined with X-ray diffraction, cuts the $\mathrm{X}$-axis at a ratio of hexanol-TMI to melamine of about 3.5:1. This is quite close to 3:1 ratio and thus a strong evidence that a three to one complex is formed.

The model experiments support the 3:1 structure of compound 1 as depicted in Fig. 1 if TMI and melamine are mixed in a 3:1 ratio. On beforehand, one could expect that a statistical mixture of complexes $(3: 1,2: 1,1: 1)$ is formed if the ratio of TMI to melamine is lower than three. Our calculations have shown that the first TMI is bonded stronger than the second one and that the third one is bonded weaker than the second one, but the differences are not that large. According to the X-ray diffraction measurements however, only the 3:1 complex is formed, irrespective the amount of melamine that is added. At first glance it seems that this in contradiction with the calculations but in our calculations the entropy effect and the crystal lattice energy of melamine are neglected. The influence of the entropy would be in favour of a statistical mixture, while the effect of the crystal lattice energy of melamine would be beneficial for the 3:1 complex. Thus, based on the evidence in favour for the 3:1 complex, the crystal lattice energy appears to be the determining factor.

\section{Rheology}

In order to obtain supramolecular polymer networks, we prepared bisimides from TMI and diols. The diols used are hexane diol, neopentyl diol and polytetramethyleneoxide (PTHF). The PTHF was an oligomer with a molecular weight of 250. The synthesis was done in the same manner as with the mono alcohols. The bisimides are, of course, bi-functional and if melamine behaves as tri-functional "crosslinker", as indicated by the modelling and the model reactions, a physical network should be formed.

Rheology is an excellent method to study the physical properties of polymer melts and is very sensitive to branching and network formation.

The molecular weight of the oligomers used here is low and the viscosity of the melt should be low and Newtonian as no entanglements are present. The viscosity of the neat bisimide, with PTHF as diol, is Newtonian and has a value of about $0.6 \mathrm{~Pa} . \mathrm{s}$ at $120^{\circ} \mathrm{C}$. This neat material thus behaves as one would expect for a low viscous substance. However, when melamine is added, the viscosity increases sharply. In Fig. 5 it can be seen that the viscosity at low shear rates is as high as $25.000 \mathrm{~Pa} . \mathrm{s}$ at $175^{\circ} \mathrm{C}$. Moreover, the viscosity is strongly dependent on the shear-rate. 
The phase angle $\delta$ is about 30 degrees, suggesting that the melt behaves as a quite strong network. Similar results were obtained with the low molecular weight diols for which the interactions were even higher. The viscosity of the hexanediol-TMI-melamine system at low shear rate was about 20.000 Pa.s even at $270^{\circ} \mathrm{C}$. This is quite remarkable for such a low molecular weight products $(416+126)$. The rheology of the PTHF-TMI-melamine mixture, as shown in Fig. 3, is typical for covalently crosslinked polymer networks.

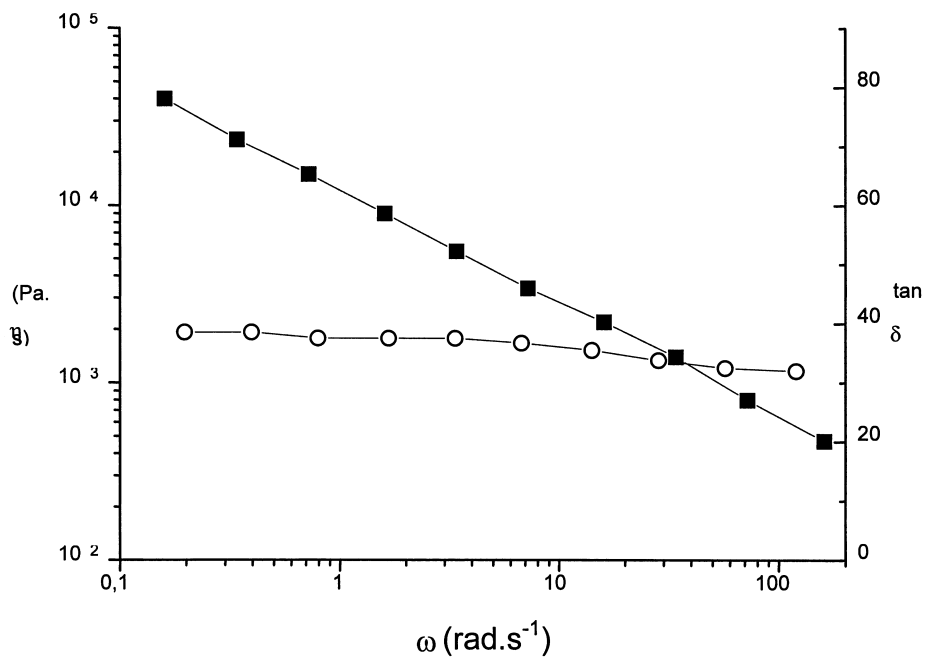

Figure 3. Rheology behaviour of PTHF(250)-TMI-melamine at $175^{\circ} \mathrm{C}(\boldsymbol{\square}=\eta)$.

However, the products investigated here are definitely not covalently crosslinked, since they are still soluble in DMSO before and after the rheology measurements The melamine can even be recovered after the rheology measurements by e.g. fractional solvent extractions. The rheological behaviour can best be explained by the existence of a physical network caused by hydrogen bonds

To check this hypothesis some strain sweep experiments were done. The results (Fig. 4) showed that at higher strain the network is destroyed. On increasing the shear strain, the viscosity drops and the phase angle strongly increases.These effects are much more pronounced than in covalently bonded networks. The rheology data are consistent with the properties of polymeric networks which is quite remarkable because the molecular weight of these compounds is only a few hundreds. This is one of the few examples of such strong 
polymeric networks obtained by low molecular weight products interacting through hydrogen bonds.

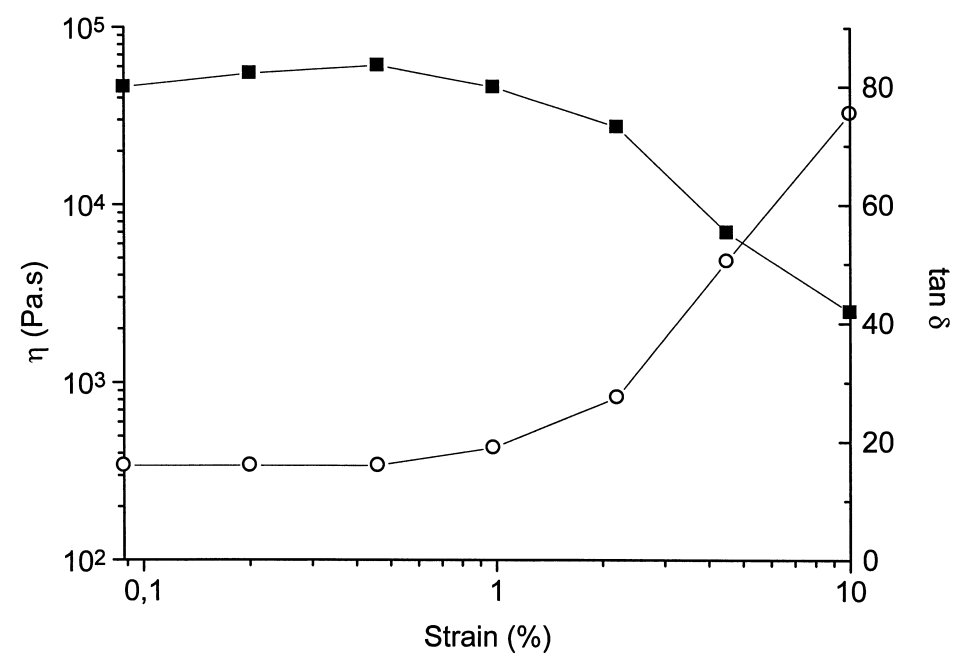

Figure 4. Strain sweep of PTHF(250)-TMI-melamine at $175^{\circ} \mathrm{C}(\boldsymbol{\square}=\eta)$.

\section{Conclusions}

Reversible, supramolecular polymer networks based on commercially available bulk chemicals, and prepared using an industrially attractive route have been prepared. The difunctional, low molecular weight polytetramethyleneoxide is functionalized with trimellitic imide, and is reversibly crosslinked with the trifunctional melamine using the well known imidediaminopyridine triple hydrogen bonding pattern. These reversible, supramolecular polymer networks show a rheological behaviour, that is typical for covalent polymer networks. Molecular modelling calculations have shown that the charge redistribution as a consequence of the binding of melamine with TMI is rather local. Therefore, the second, and also the third imide molecule, have similar complexation properties as the first one. Model studies using monofunctional imides, and analysed using IR, NMR, X-ray, DSC and DMS, show that the aimed 1:3 melamine - imide stoichiometry is obtained. The results presented here describe an industrially accessible route to use supramolecular interactions in order to obtain materials with novel properties. 


\section{Experimental and Calculation Details}

Materials. Melamine is a commercial grade of DSM. Polytetramethyleneoxide (PTHF), hexanediol, neopentyl glycol, hexanol, octanol, dodecanol, hexadecanol, trimellitic anhydride, ammonium carbonate and thionyl chloride, were purchased from Acros and used as received.

Synthesis of the imide of trimellitic anhydride. Trimellitic anhydride (192 g, $1 \mathrm{~mol})$ was molten at $280^{\circ} \mathrm{C}$ under a nitrogen blanket. Ammonium carbonate $(144 \mathrm{~g}, 1.5 \mathrm{~mol})$ was added slowly to this melt. The gaseous products that are formed were removed continuously. The melt was stirred for $30 \mathrm{~min}$, poured out and cooled down to room temperature. The yield of the reaction is nearly quantitatively. The excess ammonium carbonate decomposes in volatile components.

${ }^{1} \mathrm{H}$ NMR (DMSO-d6) $\delta: 11.5$ (s,1H, NH), 8.2 (d, 1H, Ar), 8.0 (s, 1H, Ar), 7.8 (d, 1H, Ar). ${ }^{13} \mathrm{C}$ NMR (DMSO-d6) $\delta: 168.5,165.9$ (C=O), 136.2, 136.0, 135.2, 133.2 (Ar-C), 123.4, 123.1 (Ar-C).

Preparation of the ester oligomers. The imide of trimellitic anhydride $(191 \mathrm{~g}, 1 \mathrm{~mol})$ was added to thionyl chloride $(198 \mathrm{~g}, 1.66 \mathrm{~mol})$. The mixture was heated at $80^{\circ} \mathrm{C}$ over night. The excess of thionyl chloride was distilled off and the product was washed twice with hexane. The product was dried at $80^{\circ} \mathrm{C}$ under vacuum. The yield of the reaction is nearly quantitatively.

${ }^{1} \mathrm{H}$ NMR (DMSO-do) $\delta: 11.6$ (s,1H, NH), 8.4 (d, 1H, Ar), 8.2 (s, 1H, Ar), 8.0 (d, 1H, Ar), 3.9 (s, $3 \mathrm{H}, \mathrm{OCH}_{3}$ ).

The acid chloride of trimellitic imide $(209,5 \mathrm{~g}, 1 \mathrm{~mol})$ was suspended in $600 \mathrm{ml}$ toluene. The mono alcohol $(1 \mathrm{~mol})$ or the diol $(0.5 \mathrm{~mol})$ was added and stirred at $120^{\circ} \mathrm{C}$ over night. The $\mathrm{HCl}$ that was formed during the reaction was removed by a stream of nitrogen. The toluene was removed by destillation. The yield of the reaction was in general more than $95 \%$.

The characteristics of the TMI esters that are prepared from the following mono alcohol's are: 1-Hexanol (2). $\mathrm{T}_{\mathrm{m}}=130^{\circ} \mathrm{C}, \mathrm{T}_{\mathrm{c}}=76^{\circ} \mathrm{C} .{ }^{1} \mathrm{H}$ NMR (DMSO-d6) $\delta: 11.6(\mathrm{~s}, 1 \mathrm{H}, \mathrm{NH}), 8.3(\mathrm{~d}, 1 \mathrm{H}$, Ar), 8.2 (s, 1H, Ar), 7.9 (d, 1H, Ar), $4.3\left(\mathrm{t}, 2 \mathrm{H}, \mathrm{OCH}_{2}\right), 1.7\left(\mathrm{~m}, 2 \mathrm{H}, \mathrm{CH}_{2}\right), 1.3\left(\mathrm{~m}, 6 \mathrm{H}, \mathrm{CH}_{2}\right)$, $0.9\left(\mathrm{t}, 3 \mathrm{H}, \mathrm{CH}_{3}\right) .1-$ Octanol (3). $\mathrm{T}_{\mathrm{m}}=125^{\circ} \mathrm{C}, \mathrm{T}_{\mathrm{c}}=74^{\circ} \mathrm{C} .{ }^{1} \mathrm{H}$ NMR (DMSO-d6) $\delta: 11.6(\mathrm{~s}, 1 \mathrm{H}$, $\mathrm{NH}), 8.3(\mathrm{~d}, 1 \mathrm{H}, \mathrm{Ar}), 8.2(\mathrm{~s}, 1 \mathrm{H}, \mathrm{Ar}), 8.0(\mathrm{~d}, 1 \mathrm{H}, \mathrm{Ar}), 4.3\left(\mathrm{t}, 2 \mathrm{H}, \mathrm{OCH}_{2}\right), 1.7\left(\mathrm{~m}, 2 \mathrm{H}, \mathrm{CH}_{2}\right), 1.5$ $\left(\mathrm{m}, 10 \mathrm{H}, \mathrm{CH}_{2}\right), 0.9\left(\mathrm{t}, 3 \mathrm{H}, \mathrm{CH}_{3}\right) .1$-Dodecanol (4). $\mathrm{T}_{\mathrm{m}}=135^{\circ} \mathrm{C}, \mathrm{Tc}=102^{\circ} \mathrm{C} .{ }^{1} \mathrm{H}$ NMR (DMSO-d6) $\delta: 8.5(\mathrm{~d}, 1 \mathrm{H}, \mathrm{Ar}), 8.4(\mathrm{~s}, 1 \mathrm{H}, \mathrm{Ar}), 8.2(\mathrm{~s}, 1 \mathrm{H}, \mathrm{NH}), 7.9(\mathrm{~d}, 1 \mathrm{H}, \mathrm{Ar}), 4.4(\mathrm{t}, 2 \mathrm{H}$, $\left.\mathrm{OCH}_{2}\right), 1.8\left(\mathrm{~m}, 2 \mathrm{H}, \mathrm{CH}_{2}\right), 1.3\left(\mathrm{~m}, 18 \mathrm{H}, \mathrm{CH}_{2}\right), 0.9$ (t, 3H, $\left.\mathrm{CH}_{3}\right)$. 1-Hexadecanol (5). $\mathrm{T}_{\mathrm{m}}=$ $135^{\circ} \mathrm{C}, \mathrm{T}_{\mathrm{c}}=105^{\circ} \mathrm{C} .{ }^{1} \mathrm{H}$ NMR (DMSO-d6) $\delta: 8.5(\mathrm{~d}, 1 \mathrm{H}, \mathrm{Ar}), 8.4(\mathrm{~s}, 1 \mathrm{H}, \mathrm{Ar}), 8.0(\mathrm{~d}, 1 \mathrm{H}, \mathrm{Ar})$, $7.9(\mathrm{~s}, 1 \mathrm{H}, \mathrm{NH}), 4.4\left(\mathrm{t}, 2 \mathrm{H}, \mathrm{OCH}_{2}\right), 1.8\left(\mathrm{~m}, 2 \mathrm{H}, \mathrm{CH}_{2}\right), 1.3\left(\mathrm{~m}, 26 \mathrm{H}, \mathrm{CH}_{2}\right), 0.9\left(\mathrm{t}, 3 \mathrm{H}, \mathrm{CH}_{3}\right)$.

TMI esters with diols:

1,6-Hexanediol (6). ${ }^{1} \mathrm{H}$ NMR (DMSO- $\left.d 6\right) \delta: 11.6(\mathrm{~s}, 1 \mathrm{H}, \mathrm{NH}), 8.3(\mathrm{~d}, 1 \mathrm{H}, \mathrm{Ar}), 8.1(\mathrm{~s}, 1 \mathrm{H}$, Ar), $7.9(\mathrm{~d}, 1 \mathrm{H}, \mathrm{Ar}), 4.3\left(\mathrm{t}, 4 \mathrm{H}, \mathrm{OCH}_{2}\right), 1.8\left(\mathrm{~m}, 4 \mathrm{H}, \mathrm{CH}_{2}\right), 1.5\left(\mathrm{~m}, 4 \mathrm{H}, \mathrm{CH}_{2}\right)$. Neopentyl glycol (7). ${ }^{1} \mathrm{H}$ NMR (DMSO-d6) $\delta: 11.6(\mathrm{~s}, 1 \mathrm{H}, \mathrm{NH}), 8.4(\mathrm{~d}, 1 \mathrm{H}, \mathrm{Ar}), 8.2(\mathrm{~s}, 1 \mathrm{H}, \mathrm{Ar}), 8.0(\mathrm{~d}, 1 \mathrm{H}, \mathrm{Ar})$, $4.4\left(\mathrm{~s}, 2 \mathrm{H}, \mathrm{OCH}_{2}\right), 1.2\left(\mathrm{~s}, 6 \mathrm{H}, \mathrm{CH}_{3}\right)$. Polytetramethyleneoxide (8). $\mathrm{M}_{\mathrm{n}}=250 .{ }^{1} \mathrm{H}$ NMR (DMSO-d6) $\delta: 11.6(\mathrm{~s}, 1 \mathrm{H}, \mathrm{NH}), 8.3(\mathrm{~d}, 1 \mathrm{H}, \mathrm{Ar}), 8.2$ (s, 1H, Ar), 7.9 (d, 1H, Ar), 4.3 (t, 4H, $\left.\mathrm{OCH}_{2}\right), 3.3\left(\mathrm{t}, \mathrm{nH}, \mathrm{OCH}_{2} \mathrm{O}\right), 1.8\left(\mathrm{~m}, 4 \mathrm{H}, \mathrm{CH}_{2}\right), 1.7\left(\mathrm{~m}, 4 \mathrm{H}, \mathrm{CH}_{2}\right), 1.5\left(\mathrm{~m}, 4 \mathrm{H}, \mathrm{CH}_{2}\right)$.

Preparation of the complexes (1). The complexes were prepared in the melt and in suspension. In the first method melamine is added to the molten imide. The mixture was stirred during 30 minutes at that temperature. The temperature is $10^{\circ} \mathrm{C}$ above the melting temperature of the corresponding imide. The mol ratio between the imide and melamine was $3: 1$, unless stated differently in the text. In the second method melamine was added to the 
imide that was dissolved in toluene. The mixture was stirred for $30 \mathrm{~min}$. at $135^{\circ} \mathrm{C}$. In the latter case the toluene was removed by evaporation and the complex was dried over night at $80^{\circ} \mathrm{C}$.

Measurements. ${ }^{1} \mathrm{H}-\mathrm{NMR}$ were recorded on a $200 \mathrm{MHz}$ Brucker and the IR spectra on a FTIR Spectrometer Spectrum 2000. The X-ray measurements were carried out on a Philips powder diffractometer PW 1820. The complex shear viscosity properties were determined using the parallel-plate oscillatory rheometer RMS-800 according to the ISO 6721-10 international standard. DSC experiments were done on a Netzsch DSC 200.

Calculational Details. All molecules and complexes have been constructed by means of the builder facilities of the InsightII package of Molecular Simulations (MSI). ${ }^{16)}$ Calculations have been performed at the Hartree-Fock (HF) level using the MSI Turbomole program. All atoms were described by the DZP basis sets. The geometry optimizations were carried out using the BFGS (Broyden-Fletcher-Goldfarb-Shanno) algorithm employing as convergence criteria 0.001 Hartree/Bohr for the maximum gradient, 0.001 au for the maximum displacement and $10^{-5}$ Hartree for the maximum energy change between consecutive optimization cycles. The SCF convergence criterion 'scfconv' was set to 6 , i.e. a maximum energy change of $10^{-6}$ Hartree between consecutive SCF interactions was allowed.

For studying the electron distribution in the complexes Mulliken population analyses were performed.

\section{Acknowledgement}

The authors like to thank their colleagues at DSM Research for their fruitful discussions. J. Bothmer is acknowledged for performing the rheology measurements, A. Braam and $\mathrm{H}$. Goertz for the X-ray measurements, T. Pijpers for the DSC experiments and J. Bremmers for the IR results.

\section{References}

1. a) M. Brienne, J. Gabard, M. Leclerq, J.-M. Lehn, M. Cheve, Helv. Chim. Acta., 80, 856 (1997); b) S. Kolutchin, S. Zimmerman, J. Am. Chem. Soc., 120, 9092 (1998); c) F. Seela, C. Wei, Chem. Comm., 1869 (1997); d) M. Wyler, J. de Mendoza, J. Rebek, Angew. Chem. Int. Ed. Engl., 32, 1699 (1993); e) W. Verboom, W. Smeets, A. Spek, D. Reinhoudt, O. Struck, J. Chem. Soc. Perkin Trans. 2, 223 (1997)

2. a) C.T.Seto, G.M.Whitesides, J. Am. Chem. Soc., 112, 6409 (1990). b) J.P.Mathias, E.E.Simanek, J.A.Zerkowski, C.T.Seto, G.M.Whitesides, J. Am. Chem.Soc., 116, 4316 (1994). c) J.P.Mathias, C.T.Seto, E.E.Simanek, G.M.Whitesides, J. Am. Chem. Soc., 116, 1725 (1994), see also: d) C.T.Seto, G.M.Whitesides, J. Am. Chem. Soc., 113, 712 (1991); e) C.T.Seto, J.P.Mathias, G.M.Whitesides, J. Am. Chem. Soc., 115, 1321 (1993); f) C.T.Seto, G.M.Whitesides, J. Am. Chem. Soc., 115, 905 (1993); g) G.M.Whitesides, J.P.Mathias, C.T.Seto, Science, 254, 1312 (1991); h) E.E.Simanek, S.Qiao, I.S.Choi, G.M.Whitesides, J. Org. Chem., 62, 2619 (1997). i) R.H.Vreekamp, J.P.M.van Duynhoven, M.Hubert, W.Verboom, D.N.Reinhoudt, Angew. Chem., 108, 1306 (1996); Angew. Chem. Int. Ed. Engl., 35, 1215 (1996). j) J.A.Zerkowski, C.T.Seto, D.A.Wierda, G.M.Whitesides, J. Am. Chem. Soc., 112, 9025 (1990); k) J.A.Zerkowski, C.T.Seto, G.M.Whitesides, J. Am. Chem. Soc., 114, 5473 (1992); 1) J.A.Zerkowski, G.M.Whitesides, J. Am. Chem. Soc., 116, 4298 (1994). m) C.M.Drain, K.C.Russel, J-M.Lehn, Chem. Commun., 337 (1996). n) J-M.Lehn, M.Mascal, A.DeCain, J.Fischer, J.Chem.Soc., Chem.Comm., 479 (1990). o) N.Kimizuka, S.Fujikawa, H.Kuwahara, T.Kunitake, A.Marsh, J-M.Lehn, J. Chem.Soc., Chem. Commun., 2103 (1995). p) N.Kimizuka, T.Kawasaki, K.Hirata, T.Kunitake, J. Am. Chem. Soc., 117, 6360 (1995) 
3. a) T.R.Kelly, C.Zhao, G.J.Bridges, J. Am. Chem. Soc., 111, 3744 (1989); b) T.J.Murray, S.C.Zimmerman, J. Am. Chem. Soc., 114, 4010 (1992); c) S.C.Zimmerman, T.J.Murray, Tetrahedron Lett., 35, 4077 (1994)

4. a) B.Feibush, A.Figueroa, R.Charles, K.D.Onan, P.Feibush, B.L.Karger, J. Am. Chem.Soc., 108, 3310 (1986); b) B.Feibush, M.Saha, K.Onan, B.Karger, R.Giese, J. Am. Chem. Soc., 109, 7531 (1987) c) J-M.Lehn, Makromol. Chem., Macromol. Symp., 69, 1 (1993)

5. a) J.Rebek,Jr., Pure \& Appl. Chem., 61, 1517 (1989). b) R.Kleppinger, C.P.Lillya, C.Yang, J. Am. Chem. Soc., 119, 4097 (1997). c) J.A.Zerkowski, J.C.MacDonald, G.M.Whitesides, Chem.Mater., 6,1250 (1994). d) H.Tukada, Y.Mazaki, Chem. Letters, 441 (1997). e) M.B.Chowdry, D.M.P.Mingos, A.J.P.White, D.J.Williams, Chem. Commun., 899 (1996)

6. a) R.F.M.Lange, E.W.Meijer, Macromolecules, 28, 782 (1995); b) R.F.M.Lange, E.W.Meijer, Macromol. Symp., 102, 301 (1996); c) R.F.M.Lange, F.H.Beijer, R.P.Sijbesma, R.W.W.Hooft, H.Kooijman, A.L.Spek, J.Kroon, E.W.Meijer, Angew. Chem., 109, 1006 (1997); Angew. Chem. Int. Ed. Engl., 36, 696 (1997)

7. a) T.Tjivikua, P. Ballester, J. Rebek, J. Am. Chem. Soc., 112, 1249 (1990); b) Q. Feng, T. Park, J. rebek, Science, 256, 1179 (1992)

8. a) A.Blumstein, S.B.Clough, L.Patel,R.B.Blumstein,E.C.Hsu, Macromolecules, 9, 243 (1976); b) T.Kato, J.M.J.Fréchet, Macromolecules, 22, 3818 (1989); c) U.Kamar, T.Kato, J.M.J.Fréchet, J. Am. Chem. Soc., 114, 6630 (1992); d) T.Kato, H.Kihara, U.Kamar, T.Uryu, J.M.J.Fréchet, Angew. Chem., 106, 1728 (1994); e) H.Kihara, T.Kato, T.Uryu, J.M.J.Fréchet, Chem. Mater., 8, 961 (1996)

9. a) C.Fouquey, J-M.Lehn, A-M.Levelut, Adv. Mat., 2, 254 (1990); b) M.Kotera, J-M.Lehn, JP.Vigneron, J. Chem. Soc., Chem. Commun., 197, 1994); c) M.Kotera, J-M.Lehn, JP.Vigneron, Tetrahedron, 51, 1953 (1995); d) J-M.Lehn, Makromol. Chem., Macromol. Symp., 69, 1 (1993); e) Z.Wang, L.Wang, X.Zhang, J.Shen, S.Denzinger, H.Ringsdorf, Macromol.Chem.Phys., 198, 573 (1997); f) P.Bladon, A.C.Griffin, Macromolecules, 26, 6604 (1993); g) C.Alexander, C.P.Jariwala, C-M.Lee, A.C.Griffin, Pol. Prep., 34(1), 168 (1993); h) C.Alexander, C.P.Jariwala, C-M.Lee, A.C.Griffin, Macromol. Symp., 77, 283 (1994)

10. E.P.Otocka, M.Y.Hellman, L.L.Bleyer, J. Appl. Phys., 40, 4221 (1969)

11. C.P.Lillya, R.J.Baker, S.Hütte, H.H.Winter, Y-G.Lin, J.Shi, L.C.Dickinson, J.C.W.Chien, Macromolecules, 25, 2076 (1992)

12. C. Pourcain, A. Griffin, Macromolecules, 28, 4116 (1997)

13. a) G.B.Butler, A.G.Williams, J. Pol. Sci: Pol. Chem. Ed., 17, 1117 (1979); b) R.Stadler, J.Burgert, Makromol. Chem., 187, 1681 (1986); c) C.Hilger, R.Stadler, Macromolecules, 23, 2097 (1990); d) C.Hilger, R.Stadler, Macromolecules, 25, 6670 (1992); e) A.Dardin, R.Stadler, C.Boeffel, H.W.Spiess, Makromol. Chem., 194, 3467 (1993); f) C.Hilger, M.Dräger, R.Stadler, Macromol., 25, 2498 (1992); g) R.Stadler, J.Hellmann, M.Schirle, J.Beckmann, Pol. Prep., 34(1), 100 (1993)

14. a) R.P.Sijbesma, F.H.Beijer, L.Brunsveld, B.J.B.Folmer, J.H.K.K.Hirschberg, R.F.M.Lange, J.K.L.Lowe, E.W.Meijer, Science, 278, 1601, (1997); b) F. Beijer, R. Sijbesma, H. Kooijman, A. Spek, E.W. Meijer, J. Am. Chem. Soc., 120, 6761 (1998); c) B. Folmer, R. Sijbesma, E.W. Meijer, Chem. Comm., 1847 (1998); d) R.F.M.Lange, M. van Gurp, E.W.Meijer, J. Pol. Sci. A. Pol. Chem., 37, 3657 (1999)

15. W.J. Hehre, L. Radom, P.v.R. Scheyler, J.A. Pople. Ab initio Molecular Orbital Theory. John Wiley \& Sons, Inc., 1986

16. Computational results obtained using software programs from Molecular Simuations-ab initio calculations were done with the Turmomole program and graphical displays were printed out frem InsightII molecular modelling system. 